\title{
Preoperative characteristics and surgical outcomes of acute intramural hematoma involving the ascending aorta: A propensity score-matched analysis
}

\author{
Akihito Matsushita, MD, ${ }^{\mathrm{a}, \mathrm{b}}$ Toshihiro Fukui, MD, ${ }^{\mathrm{b}}$ Minoru Tabata, MD, MPH, ${ }^{\mathrm{b}, \mathrm{c}}$ \\ Yasunori Sato, $\mathrm{PhD},{ }^{\mathrm{d}}$ and Shuichiro Takanashi, $\mathrm{MD}^{\mathrm{b}}$
}

\begin{abstract}
Objective: We aimed to evaluate the preoperative characteristics and surgical outcomes of acute type A intramural hematoma.

Methods: Between January 2000 and June 2011, 460 consecutive patients underwent emergency open surgery for type A acute aortic syndrome at Sakakibara Heart Institute. Among these patients, 121 had intramural hematoma and 339 had typical aortic dissection. We compared the clinical characteristics and surgical outcomes using propensity score matching.
\end{abstract}

Results: In all patients, the intramural hematoma group had an older age $(69.2 \pm 10.4$ years vs $63.4 \pm 13.5$ years; $P<.001)$, included a higher ratio of female patients $(56.2 \%$ vs $44.0 \%, P=.020)$, and more frequently had hypertension ( $94.2 \%$ vs $83.5 \%, P=.005)$, hyperlipidemia $(25.6 \%$ vs $12.7 \%$, $P<.001)$, and cardiac tamponade $(33.1 \%$ vs $18.3 \%, P<.001)$ than patients with aortic dissection. Cerebral malperfusion $(0.8 \%$ vs $5.3 \%, P=.033)$, myocardial malperfusion $(0.8 \%$ vs $8.2 \%, P=.002)$, lower limb malperfusion $(1.7 \%$ vs $7.9 \%, P=.015)$, Marfan syndrome $(0 \%$ vs $3.5 \%, P=.042)$, and aortic valve insufficiency $(2.5 \%$ vs $15.0 \%, P<.001)$ were less frequently observed in the intramural hematoma group than in the aortic dissection group. After propensity score matching, 116 matched pairs were created. In the matched analysis, operative mortality was $0.9 \%$ in the intramural hematoma group $(1 / 116)$ and $3.4 \%$ in the aortic dissection group $(4 / 116, P=.179)$. The intramural hematoma group demonstrated higher actuarial 1- and 5-year survivals than the aortic dissection group $(99.1 \%$ vs $93.6 \%$ and $97.3 \%$ vs $85.9 \%$, respectively, $P=.006$ ). In the multivariate analysis, intramural hematoma was shown to be associated with lower midterm mortality (hazard ratio, $0.316 ; 95 \%$ confidence interval, 0.102-0.974; $P=.045$ ).

Conclusions: Patients with intramural hematoma have different preoperative clinical characteristics compared with patients with aortic dissection. Emergency open surgery for type A intramural hematoma demonstrated low operative mortality and excellent 5-year survival. ( $\mathbf{J}$ Thorac Cardiovasc Surg 2016;151:351-8)

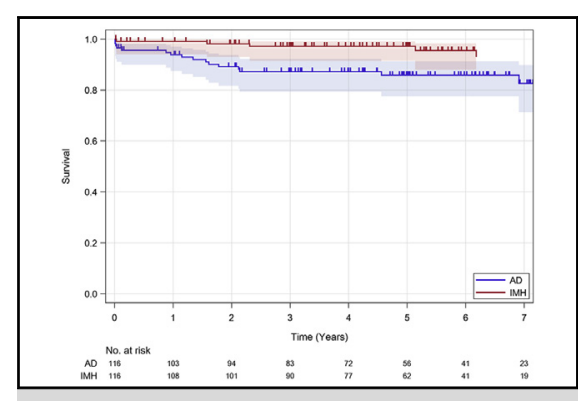

Kaplan-Meier survival analysis for all causes of death with $95 \%$ confidence limits in matched patients.

\section{Central Message}

Clinical characteristics of IMH were different from those of AD. Emergency surgery for IMH showed excellent results.

\section{Perspective}

The optimal initial treatment strategy for IMH remains controversial. Emergency open surgery for acute type A IMH can be performed using the same operative strategy and procedure as those for patients with AD. Some patients require late reoperations for the aorta related to IMH. Patients with IMH should be followed up carefully, similar to patients with AD.

See Editorial Commentary page 359.

See Editorial page 294.

\footnotetext{
From the a Department of Cardiovascular Surgery, Chiba Medical Center, Chiba, Japan; ' Department of Cardiovascular Surgery, Sakakibara Heart Institute, Tokyo, Japan; ' Department of Cardiovascular Surgery, Tokyo Bay Urayasu Ichikawa Medical Center, Chiba, Japan; and ${ }^{\mathrm{d}}$ The Clinical Research Center, Graduate School of Medicine, Chiba University, Chiba, Japan.

Received for publication Jan 29, 2015; revisions received Sept 7, 2015; accepted for publication Sept 10, 2015; available ahead of print Oct 12, 2015.

Address for reprints: Akihito Matsushita, MD, Department of Cardiovascular Surgery, Chiba Medical Center, 1-7-1 Minami-cho, Chuo-ku, Chiba 260-0842, Japan (E-mail: matsushita@ seikeikai-cmc.jp). $0022-5223 / \$ 36.00$

Copyright (c) 2016 by The American Association for Thoracic Surgery http://dx.doi.org/10.1016/j.jtcvs.2015.09.055
}

Acute intramural hematoma (IMH) is a life-threatening disease requiring emergency treatment. This emergency is similar to, but pathologically different from, acute aortic dissection (AD). Two different pathophysiologic processes have been suggested to lead to the occurrence of IMH. One cause is spontaneous rupture of the aortic vasa vasorum, leading to a hematoma in the media of the aortic wall without intimal disruption. ${ }^{1}$ The other process is an atherosclerotic ulcer, which penetrates into the internal media of the aortic wall. ${ }^{2}$ Uchida and colleagues ${ }^{3}$ analyzed the 


\section{Abbreviations and Acronyms \\ $\mathrm{AD}=$ aortic dissection \\ $\mathrm{CI}=$ confidence interval \\ $\mathrm{CT}=$ computed tomography \\ $\mathrm{HR}=$ hazard ratio \\ $\mathrm{IMH}=$ intramural hematoma \\ $\mathrm{TAR}=$ total arch replacement}

clinical, surgical, and histopathologic characteristics of IMH and concluded that patients with IMH have a high risk of adventitial rupture. Although the optimal initial treatment strategy for IMH remains controversial, early surgery for all patients with type A IMH has been recommended because of their poor prognosis with medical treatment. $^{3,4}$

Several investigators have analyzed the surgical outcomes in patients with type A IMH and concluded that patients with IMH have more favorable results compared with those with $\mathrm{AD}{ }^{5,6}$ However, there are few reports regarding late operative outcomes in patients with $\mathrm{IMH}^{7,8}$ We aimed to compare preoperative characteristics and short-term and midterm outcomes after emergency surgery between patients with IMH and patients with AD.

\section{PATIENTS AND METHODS \\ Patient Population}

This study was approved by the institutional review board, and a waiver of informed consent was obtained. Between January 2000 and June 2011, 121 patients with IMH and 339 patients with AD underwent emergency open surgery at Sakakibara Heart Institute. All of these patients had emergency surgery within 24 hours after admission to our hospital. The median follow-up was 51 months, ranging from 1 to 114 months.

The most common initial symptoms were chest, abdominal, or back pain, and there were some patients with a loss of consciousness in the both groups. The diagnosis was made with contrast computed tomography (CT) in all patients. IMH was defined as a thickened aortic wall caused by intramural hemorrhage, with a crescent or circular high attenuation area along the aortic wall without enhancement on contrast-enhanced CT, indicating noncommunication with the aortic lumen. IMH has been defined by the absence of an intimal tear. ${ }^{5}$ In this study, however, we included AD with a totally thrombosed false lumen in the IMH group because it is difficult to confirm the absence of intimal tears in the entire aorta without complete aortography or autopsy. ${ }^{6,8,9}$ Our indication of surgery for IMH included cardiac tamponade, an ascending aorta $45 \mathrm{~mm}$ or greater, and thickness of a hematoma in the false lumen greater than $7 \mathrm{~mm}$.

\section{Data Collection and Definitions}

Perioperative data were collected from patients' medical records. Cardiac tamponade was defined as a cardiogenic shock with a systolic blood pressure of $90 \mathrm{~mm} \mathrm{Hg}$ or less, associated with pericardial effusion, which was confirmed by CT or echocardiography. Cerebral malperfusion was defined as newly developed neurologic deficits and the presence of false lumen in any cerebral branch arteries on the CT images. Myocardial malperfusion was defined as electrocardiogram change indicating myocardial ischemia and elevated myocardial enzymes. Lower limb malperfusion was defined as newly developed lower limb pain, coldness, paralysis/parenthesis, or loss of pulses. Mesenteric malperfusion was diagnosed by CT showing impaired flow in the mesenteric artery or celiac artery and abdominal findings, such as distension, pain, and tenderness. Stroke was defined as a central neurologic deficit persisting for more than 72 hours after surgery. All strokes were confirmed by CT or magnetic resonance imaging. Respiratory failure was defined as a requirement for mechanical ventilation for more than 48 hours postoperatively. Operative mortality was defined as any death within 30 days after surgery or before discharge. IMH- or AD-related events were defined as follows: new IMH or dissection, need for further surgical treatment, aortic rupture, and sudden unexplained death. IMH- or AD-related deaths were defined as follows: death from aortic rupture, sudden unexplained death, and death after further surgical treatment. Our indications of reoperation for the aorta related to $\mathrm{IMH}$ or $\mathrm{AD}$ were as follows: rupture or impending rupture of the aorta, dilatation of the aorta $55 \mathrm{~mm}$ or greater, rapid dilatation of the aorta ( $>10 \mathrm{~mm} / \mathrm{y})$, graft infection, and severe aortic valve insufficiency.

\section{Operative Strategy and Procedure}

All of the operations were performed through a median sternotomy. The initial arterial cannula was mostly placed in the femoral artery. The left ventricular apex or axillary artery was cannulated if the femoral artery was unavailable. Femoral arterial cannulation was avoided when distal aortic aneurysm, iliofemoral disease, femoral artery dissection, or limb ischemia was present. Our strategy of selection of the cannulation site has been described. ${ }^{10}$ In all patients, a combination of antegrade and retrograde cardioplegia was used. The patient was cooled down to $25^{\circ} \mathrm{C}$ for circulatory arrest. A single-branched prosthesis was used in ascending aortic or hemiarch replacement, and a 4-branched prosthesis was used in total arch replacement (TAR). Our indication of TAR was aortic arch dilatation $(\geq 45 \mathrm{~mm})$, a penetrating atherosclerotic ulcer in the aortic arch, and an intimal tear located in the distal aortic arch or the greater curvature of the aortic arch.

The proximal side of the aorta was repaired with gelatin resorcinol formaldehyde glue and double strips (a vascular graft strip or Teflon felt strip inside and a Teflon felt strip outside) at the level of the sinotubular junction. The distal side of the aorta was repaired with double Teflon felt strips in ascending aortic or hemiarch replacement. A folded elephant trunk graft was inserted into the distal aorta, reinforced with an outer Teflon felt strip, and anastomosed to the aorta with a running suture in the TAR.

In ascending aortic or hemiarch replacement, distal anastomosis was performed under hypothermic circulatory arrest with retrograde cerebral perfusion from the superior vena cava. After distal anastomosis, whole body circulation was resumed through the branch of the prosthesis and the patient was fully rewarmed up to $35^{\circ} \mathrm{C}$. Proximal anastomosis was performed during rewarming.

In TAR, we used the arch-first technique with retrograde cerebral perfusion between January 2000 and August 2006. Subsequently, we introduced antegrade selective cerebral perfusion and separate lower-body perfusion in 2006. ${ }^{11}$ Since 2006, distal anastomosis has been performed using the elephant trunk technique under hypothermic circulatory arrest. We used selective antegrade cerebral perfusion and inserted balloon catheters into 3 cerebral branches. After distal anastomosis, lower body circulation was resumed through a cannula that was placed in the common femoral artery with balloon occlusion of the elephant trunk, and the patient was rewarmed up to $30^{\circ} \mathrm{C}$. Cerebral branches were separately anastomosed to the branches of the prosthesis. After reconstructing cerebral branches, whole body circulation was resumed through the fourth branch of the prosthesis and the patient was rewarmed up to $35^{\circ} \mathrm{C}$. Proximal anastomosis was performed during rewarming. TAR using the stepwise distal anastomosis technique, selective antegrade cerebral perfusion, and separate lower body perfusion has been reported in detail by Matsuyama and colleagues. ${ }^{11}$

\section{Statistical Analysis}

Summary statistics were performed using frequencies and proportions for categoric data, and mean \pm standard deviation or median if appropriate for continuous variables. Univariate analyses were carried out using the 
TABLE 1. Preoperative characteristics of the patients

\begin{tabular}{|c|c|c|c|c|c|c|c|c|}
\hline \multirow[b]{2}{*}{ Variables } & \multicolumn{4}{|c|}{ All patients } & \multicolumn{4}{|c|}{ Propensity-matched pairs } \\
\hline & $\begin{array}{l}\text { IMH group } \\
(n=121)\end{array}$ & $\begin{array}{l}\text { AD group } \\
(n=339)\end{array}$ & $\begin{array}{c}\text { Standardized } \\
\text { difference }\end{array}$ & $\begin{array}{c}P \\
\text { value }\end{array}$ & $\begin{array}{l}\text { IMH group } \\
(\mathbf{n}=116)\end{array}$ & $\begin{array}{l}\text { AD group } \\
(n=116)\end{array}$ & $\begin{array}{c}\text { Standardized } \\
\text { difference }\end{array}$ & $\begin{array}{c}P \\
\text { value }\end{array}$ \\
\hline Age $(y ;$ mean $\pm S D)$ & $69.2 \pm 10.4$ & $63.4 \pm 13.5$ & 0.48 & $<.001$ & $68.8 \pm 10.4$ & $67.7 \pm 11.6$ & 0.13 & .242 \\
\hline Female & $68(56.2 \%)$ & $149(44.0 \%)$ & 0.25 & .020 & $64(55.2 \%)$ & $64(55.2 \%)$ & 0.0 & 1.000 \\
\hline Hypertension & $114(94.2 \%)$ & $283(83.5 \%)$ & 0.34 & .005 & $109(94.0 \%)$ & $111(95.7 \%)$ & -0.08 & .317 \\
\hline Hyperlipidemia & $31(25.6 \%)$ & $43(12.7 \%)$ & 0.33 & $<.001$ & $26(22.4 \%)$ & $24(20.7 \%)$ & 0.04 & .564 \\
\hline Diabetes mellitus & $6(5.0 \%)$ & $16(4.7 \%)$ & 0.01 & .887 & $6(5.2 \%)$ & $7(6.0 \%)$ & -0.03 & .706 \\
\hline Hemodialysis & $0(0 \%)$ & $2(0.6 \%)$ & -0.11 & 1.000 & $0(0 \%)$ & $0(0 \%)$ & 0.0 & NA \\
\hline Cardiac tamponade & $40(33.1 \%)$ & $62(18.3 \%)$ & 0.34 & $<.001$ & $35(30.2 \%)$ & $33(28.4 \%)$ & 0.04 & .564 \\
\hline Preoperative intubation & $9(7.4 \%)$ & $28(8.3 \%)$ & -0.03 & .927 & $9(7.8 \%)$ & $7(6.0 \%)$ & 0.07 & .527 \\
\hline Preoperative neurologic deficit & $11(9.1 \%)$ & $34(10.0 \%)$ & -0.03 & .765 & $10(8.6 \%)$ & $13(11.2 \%)$ & -0.09 & .257 \\
\hline Cerebral malperfusion & $1(0.8 \%)$ & $18(5.3 \%)$ & -0.26 & .033 & $1(0.9 \%)$ & $1(0.9 \%)$ & 0.0 & NA \\
\hline Myocardial malperfusion & $1(0.8 \%)$ & $28(8.2 \%)$ & -0.36 & .002 & $1(0.9 \%)$ & $1(0.9 \%)$ & 0.0 & NA \\
\hline Mesenteric malperfusion & $2(1.7 \%)$ & $9(2.7 \%)$ & -0.07 & .736 & $2(1.7 \%)$ & $2(1.7 \%)$ & 0.0 & 1.000 \\
\hline Lower limb malperfusion & $2(1.7 \%)$ & $27(7.9 \%)$ & -0.29 & .015 & $2(1.7 \%)$ & $1(0.9 \%)$ & 0.07 & .317 \\
\hline Aortic valve insufficiency & $3(2.5 \%)$ & $51(15.0 \%)$ & -0.45 & $<.001$ & $3(2.6 \%)$ & $3(2.6 \%)$ & 0.0 & NA \\
\hline Previous cardiac surgery & $3(2.5 \%)$ & $12(3.5 \%)$ & -0.06 & .769 & $3(2.6 \%)$ & $2(1.7 \%)$ & 0.06 & .564 \\
\hline Marfan syndrome & $0(0 \%)$ & $12(3.5 \%)$ & -0.27 & .042 & $0(0 \%)$ & $0(0 \%)$ & 0.0 & NA \\
\hline \multicolumn{9}{|l|}{ Initial symptom } \\
\hline Body pain & $115(95.0 \%)$ & $315(92.9 \%)$ & 0.09 & .551 & $110(94.8 \%)$ & $108(93.1 \%)$ & 0.07 & .783 \\
\hline Limb pain & $2(1.7 \%)$ & $19(5.6 \%)$ & -0.21 & .081 & $0(0 \%)$ & $0(0 \%)$ & 0.0 & NA \\
\hline Loss of consciousness & $12(9.9 \%)$ & $37(10.9 \%)$ & -0.03 & .760 & $11(9.5 \%)$ & $16(13.8 \%)$ & -0.13 & .306 \\
\hline Paralysis & $3(2.5 \%)$ & $15(4.4 \%)$ & -0.10 & .425 & $3(2.6 \%)$ & $2(1.7 \%)$ & 0.06 & .564 \\
\hline
\end{tabular}

Standardized difference: difference in means or proportions divided by standard error. $I M H$, Intramural hematoma; $A D$, aortic dissection; $S D$, standard deviation; $N A$, not applicable.

$t$ test or Mann-Whitney $U$ test for continuous variables and Fisher exact test for categoric variables.

Propensity scores were calculated involving the following preoperative variables: age, sex, hypertension, hyperlipidemia, diabetes mellitus, hemodialysis, cardiac tamponade, preoperative intubation, preoperative neurologic deficit, cerebral malperfusion, myocardial malperfusion, mesenteric malperfusion, lower limb malperfusion, aortic valve insufficiency, previous cardiac surgery, and Marfan syndrome. Matching was performed by using a Greedy 5-to-1 Digit-Matching algorithm. After propensity score matching, 116 matched pairs were created (Table 1). In propensity-matched patients, univariate analyses were carried out using the paired $t$ test or Wilcoxon signed-rank test for continuous variables and McNemar's test for categoric variables. Previous reports suggested standard criteria for using the propensity score-matching method, ${ }^{12,13}$ and we followed them in this analysis.

For time-to-event outcomes, the times that elapsed until a first event were compared using the log-rank test or stratified log-rank test, whereas the Kaplan-Meier method was used to estimate the absolute risk of each event for each group. We examined a difference in midterm mortality between IMH and $\mathrm{AD}$ in all patients and propensity matched patients using a Cox proportional hazards model. There were 34 patients with midterm mortality in all patients and 18 patients with midterm mortality in propensity-matched patients. We decided to force in the Cox hazards model analysis only 3 variables for all patients and 2 variables for propensitymatched patients because of the low numbers of events. Independent factors in the model for all patients included IMH, propensity score, and additional concomitant procedures that mean any other procedure than ascending aorta or hemiarch replacement, that is, TAR, aortic root repair or replacement, aortic valve repair or replacement, and coronary artery bypass grafting. Independent factors in the model for propensitymatched patients included IMH and additional concomitant procedures (Table 2).

Results are expressed as hazard ratios (HRs) with $95 \%$ confidence intervals (CIs). All of the data were analyzed according to the intentionto-treat principle, all of the comparisons were planned, and the tests were 2-sided. Statistical analyses were performed by using SPSS version 22.0 (IBM Corp, Armonk, NY), SAS software version 9.3 (SAS Institute, Inc, Cary, NC), and the R statistical program, version 3.00.

TABLE 2. Univariate and multivariate analyses for predictors of midterm mortality

\begin{tabular}{|c|c|c|c|c|}
\hline \multirow[b]{2}{*}{ Subject of analysis } & \multirow[b]{2}{*}{ Predictors } & \multirow[b]{2}{*}{ Univariate } & \multicolumn{2}{|c|}{ Multivariate } \\
\hline & & & Hazard ratio $(95 \%$ CI $)$ & $P$ value \\
\hline \multirow[t]{3}{*}{ All patients } & $\mathrm{IMH}$ & 0.043 & $0.341(0.113-1.026)$ & .056 \\
\hline & Propensity score & 0.159 & $1.250(0.115-13.597)$ & .854 \\
\hline & Additional concomitant procedures & 0.322 & $1.211(0.584-2.512)$ & .607 \\
\hline \multirow[t]{2}{*}{ Matched patients } & IMH & 0.023 & $0.316(0.102-0.974)$ & .045 \\
\hline & Additional concomitant procedures & 0.096 & $2.189(0.856-5.597)$ & .102 \\
\hline
\end{tabular}

Additional concomitant procedures: TAR, aortic root repair or replacement, aortic valve repair or replacement, coronary artery bypass grafting. $C I$, Confidence interval; $I M H$, intramural hematoma. 
TABLE 3. Operative data

\begin{tabular}{|c|c|c|c|c|c|c|}
\hline \multirow[b]{2}{*}{ Variables } & \multicolumn{3}{|c|}{ All patients } & \multicolumn{3}{|c|}{ Propensity-matched pairs } \\
\hline & $\begin{array}{l}\text { IMH group } \\
(\mathbf{n}=121)\end{array}$ & $\begin{array}{c}\text { AD group } \\
(n=339)\end{array}$ & $\begin{array}{c}P \\
\text { value }\end{array}$ & $\begin{array}{l}\text { IMH group } \\
(\mathbf{n}=116)\end{array}$ & $\begin{array}{c}\text { AD group } \\
(n=116)\end{array}$ & $\begin{array}{c}P \\
\text { value }\end{array}$ \\
\hline Ascending aortic/hemiarch replacement & $100(82.6 \%)$ & $238(70.2 \%)$ & .007 & $95(81.9 \%)$ & $82(70.7 \%)$ & .028 \\
\hline TAR & $21(17.4 \%)$ & $101(29.8 \%)$ & .007 & $21(18.1 \%)$ & $34(29.3 \%)$ & .028 \\
\hline Concomitant procedures & $14(11.6 \%)$ & $113(33.3 \%)$ & $<.001$ & $14(12.1 \%)$ & $11(9.5 \%)$ & .414 \\
\hline Aortic root repair or replacement & $1(0.8 \%)$ & $52(15.3 \%)$ & $<.001$ & $1(0.9 \%)$ & $3(2.6 \%)$ & .317 \\
\hline Aortic valve repair or replacement & $6(5.0 \%)$ & $10(2.9 \%)$ & .455 & $6(5.2 \%)$ & $1(0.9 \%)$ & .025 \\
\hline Coronary artery bypass grafting & $5(4.1 \%)$ & $33(9.7 \%)$ & .085 & $5(4.3 \%)$ & $3(2.6 \%)$ & .317 \\
\hline Mean $( \pm \mathrm{SD})$ operation time $(\mathrm{min})$ & $235.5 \pm 67.3$ & $271.7 \pm 87.0$ & $<.001$ & $237.3 \pm 68.2$ & $270.4 \pm 94.1$ & .004 \\
\hline Mean $( \pm \mathrm{SD})$ cardiopulmonary bypass time (min) & $124.1 \pm 35.1$ & $155.3 \pm 58.2$ & $<.001$ & $124.6 \pm 35.7$ & $153.2 \pm 61.4$ & $<.001$ \\
\hline Mean $( \pm \mathrm{SD})$ aortic crossclamping times $(\mathrm{min})$ & $86.5 \pm 27.5$ & $110.4 \pm 47.6$ & $<.001$ & $87.0 \pm 28.0$ & $102.0 \pm 40.5$ & $<.001$ \\
\hline
\end{tabular}

$I M H$, Intramural hematoma; $A D$, aortic dissection; $T A R$, total arch replacement; $S D$, standard deviation.

\section{RESULTS}

\section{Preoperative Characteristics of All Patients}

The patients' characteristics in both groups are shown in Table 1 . The IMH group had a significantly older age and higher ratio of female patients than the $\mathrm{AD}$ group. Hypertension, hyperlipidemia, and cardiac tamponade were more frequently observed in the IMH group than in the AD group. Malperfusion (cerebral, myocardial, lower limb), Marfan syndrome, and aortic valve insufficiency were less frequently observed in the IMH group than in the $\mathrm{AD}$ group.

\section{Operative Outcomes of All Patients}

Operative data are shown in Table 3. TAR $(17.4 \%$ vs $29.8 \%, P=.007)$ and concomitant procedures $(11.6 \%$ vs $33.3 \%, P<.001)$ were less frequently performed in the $\mathrm{IMH}$ group than in the $\mathrm{AD}$ group.

Operative outcomes are shown in Table 4. The operative mortality was lower in the IMH group $(0.8 \%, 1 / 121)$ than in the $\mathrm{AD}$ group $(5.3 \%, 18 / 339, P=.033)$. In the IMH group, the cause of operative death was stroke. In the $\mathrm{AD}$ group, causes of operative death were stroke in 8 patients, multiple organ failure in 4 patients, acute myocardial infarction in 3 patients, and mediastinitis in 3 patients.

\section{Midterm Outcomes of All Patients}

During the follow-up period, 4 patients in the IMH group died. The cause of death was not related to IMH (pneumonia in 2 patients and heart failure in 2 patients). Thirty patients died in the AD group. Of these, AD-related death occurred in 11 patients (sudden unexplained death in 6, rupture of dissected aorta in 1, pneumonia after reoperation in 2 , and stroke after reoperation in 2 patients), and death in the other 19 patients was not related to $\mathrm{AD}$ (stroke unrelated to surgery or dissection in 5, gastrointestinal disease in 4 , cancer in 3, renal failure in 3, heart failure in 1, pneumonia in 1 , sepsis in 1, and arrhythmia in 1 patient). Kaplan-Meier analysis estimated that actuarial 1-, 3-, and 5-year survivals were $99.2 \%, 97.3 \%$, and $97.3 \%$, respectively, in the IMH group, and these were significantly higher than those in the $\mathrm{AD}$ group $(91.6 \%, 87.2 \%$, and $85.2 \%$, respectively, $P=.002$ ) (Figure $1, A$ ). As a result of multivariate analysis, IMH was not shown to be associated with lower midterm mortality after adjustment of propensity score and additional concomitant procedures (HR, 0.341; 95\% CI, 0.113-1.026; $P=.056)$ (Table 2).

A total of 47 patients required reoperation for the aorta related to IMH or $\mathrm{AD}$. Of these, 13 patients were in the $\mathrm{IMH}$ group and 34 patients were in the $\mathrm{AD}$ group. Kaplan-Meier analysis estimated that actuarial 1-, 3-, and

TABLE 4. Operative outcomes

\begin{tabular}{|c|c|c|c|c|c|c|}
\hline \multirow[b]{2}{*}{ Variables } & \multicolumn{3}{|c|}{ All patients } & \multicolumn{3}{|c|}{ Propensity-matched pairs } \\
\hline & $\begin{array}{c}\text { IMH group } \\
(\mathrm{n}=\mathbf{1 2 1})\end{array}$ & $\begin{array}{c}\text { AD group } \\
(\mathbf{n}=339)\end{array}$ & $\begin{array}{c}P \\
\text { value }\end{array}$ & $\begin{array}{c}\text { IMH group } \\
(\mathbf{n}=116)\end{array}$ & $\begin{array}{c}\text { AD group } \\
(\mathrm{n}=116)\end{array}$ & $\begin{array}{c}P \\
\text { value }\end{array}$ \\
\hline Operative death & $1(0.8 \%)$ & $18(5.3 \%)$ & .033 & $1(0.9 \%)$ & $4(3.4 \%)$ & .179 \\
\hline Stroke & $6(5.0 \%)$ & $25(7.4 \%)$ & .489 & $6(5.2 \%)$ & $10(8.6 \%)$ & .285 \\
\hline Respiratory failure & $16(13.2 \%)$ & $57(16.8 \%)$ & .359 & $16(13.8 \%)$ & $27(23.3 \%)$ & .056 \\
\hline Reexploration for bleeding & $5(4.1 \%)$ & $14(4.1 \%)$ & .795 & $5(4.3 \%)$ & $4(3.4 \%)$ & .706 \\
\hline Deep sternal infection & $4(3.3 \%)$ & $13(3.8 \%)$ & .982 & $4(3.4 \%)$ & $2(1.7 \%)$ & .414 \\
\hline Median days of intensive care unit stay (range) & $3(1-28)$ & $2(1-46)$ & .904 & $3(1-28)$ & $3(1-46)$ & .046 \\
\hline Median days of hospital stay (range) & $18(5-142)$ & $21(1-125)$ & .029 & $18(5-142)$ & $23(4-125)$ & .502 \\
\hline Prolonged hospitalization $(>30 \mathrm{~d})$ & $13(10.7 \%)$ & $47(13.8 \%)$ & .387 & $13(11.2 \%)$ & $22(19.0 \%)$ & .103 \\
\hline
\end{tabular}

$I M H$, Intramural hematoma; $A D$, aortic dissection. 

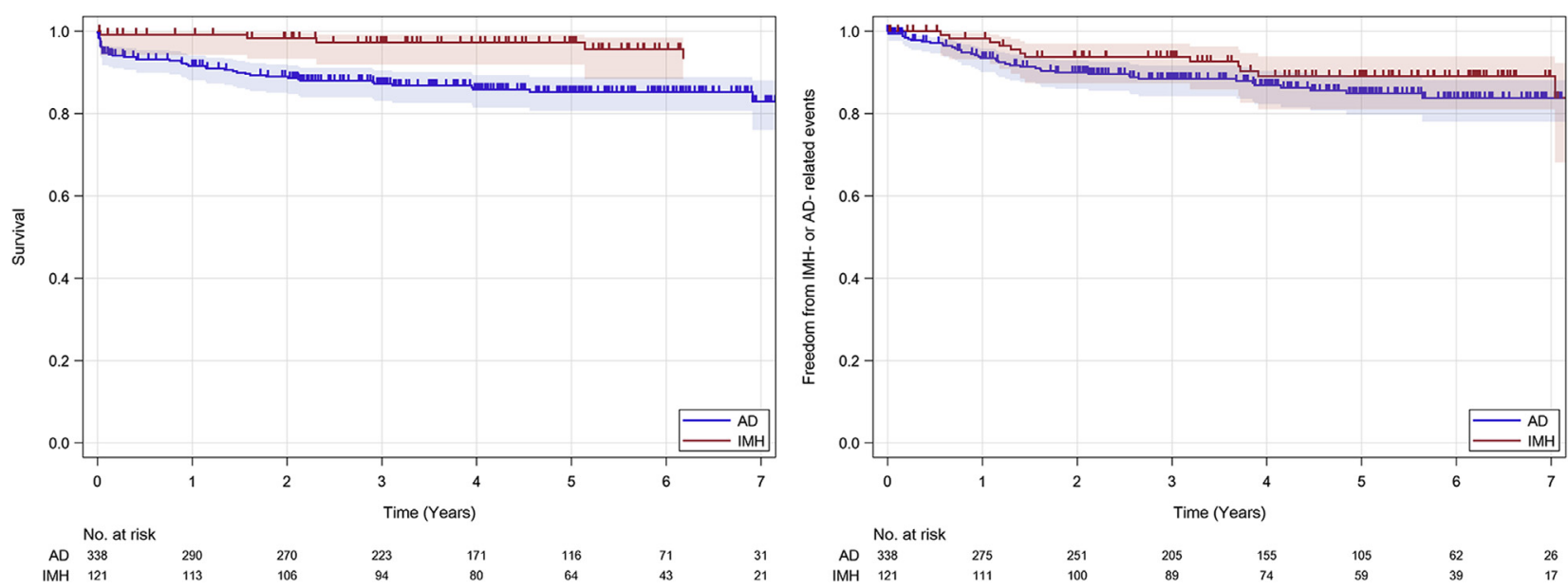

A

B

FIGURE 1. A, Kaplan-Meier analysis for freedom from any cause of death with $95 \%$ confidence limits in all patients. B, Kaplan-Meier analysis for freedom from IMH- or AD-related events with $95 \%$ confidence limits in all patients. $A D$, Aortic dissection; $I M H$, intramural hematoma.

5-year IMH or AD-related event-free rates were 98.2\%, $93.8 \%$, and $89.1 \%$ in the IMH group, respectively, and $93.7 \%, 88.7 \%$, and $85.1 \%$ in the AD group, respectively $(P=.358)$ (Figure $1, B)$. The causes of reoperation and site of operation are shown in Figure 2. The reoperative mortality rate was $0 \%$ in the IMH group $(0 / 13)$ and $5.9 \%$ in the $\mathrm{AD}$ group (2/34). The cause of 2 reoperative deaths was stroke.

\section{Operative Outcomes of Propensity Score-Matched Patients}

Preoperative and perioperative data of the propensitymatched patients are listed in Tables 1 and 3. These matched pairs were well balanced for all known covariates (Table 1). The operative mortality was similar between patients in the IMH group $(0.9 \%, 1 / 116)$ and patients in the $\mathrm{AD}$ group $(3.4 \%, 4 / 116, P=.370)$ (Table 4).

\section{Midterm Outcomes of Propensity Score-Matched Patients}

Kaplan-Meier analysis estimated that actuarial 1-, 3-, and 5-year survivals were $99.1 \%, 97.2 \%$, and $97.2 \%$, respectively, in the IMH group, and these were significantly higher than those in the AD group $(93.8 \%, 87.2 \%$, and $85.9 \%$, respectively, $P=.006$ ) (Figure $3, A$ ). Kaplan-Meier analysis also estimated that actuarial 1-, 3-, and 5-year IMH- or AD-related event-free rates were 99.1\%, 95.3\%, and $90.4 \%$ in the IMH group, respectively, and $96.2 \%$, $89.1 \%$, and $83.6 \%$ in the AD group, respectively $(P=.290)$ (Figure 3, B). As a result of multivariate analysis, IMH was shown to be associated with lower midterm mortality after adjustment of additional concomitant procedures (HR, 0.316; 95\% CI, 0.102-0.974; $P=.045$ ) (Table 2).

\section{DISCUSSION}

The present study showed that the preoperative clinical characteristics of patients with IMH and AD were different. Most likely because of this difference, emergency open surgery for IMH required simpler procedures and demonstrated lower operative mortality and higher 5-year survival compared with AD.

IMH has been shown to occur in older patients and more often in female patients compared with $\mathrm{AD},{ }^{3,5}$ as our study showed. Patients with IMH generally presented with less severe clinical findings than patients with $\mathrm{AD}$; however, patients with IMH more frequently had cardiac tamponade. Uchida and colleagues ${ }^{3}$ reported that the hematoma in IMH was located in the media closer to the adventitia than that in $\mathrm{AD}$, indicating that the false lumen wall of IMH is thinner than that of AD. This finding might be a reason why the IMH group more frequently had cardiac tamponade than the $\mathrm{AD}$ group in our study. Organ malperfusion and aortic valve insufficiency were less frequently observed in the $\mathrm{IMH}$ group than in the $\mathrm{AD}$ group. Malperfusion occurs when the false lumen compresses the true lumen perfusing the organ. Because the false lumen pressure is lower than the true lumen pressure in $\mathrm{IMH}^{8}$ malperfusion is not a common complication in IMH.

The operative mortality rates in the IMH and AD groups were low $(0.8 \%$ and $5.3 \%$, respectively) in our study. Recent studies have reported that operative mortality ranges from $4.3 \%$ to $10.9 \%$ in patients with $\mathrm{IMH}^{3,5,8,14}$ and from $8.9 \%$ to $23.9 \%$ in patients with $\mathrm{AD} .{ }^{15-20}$ The previously published study showed that surgical outcomes of IMH were significantly better than those of $\mathrm{AD} .^{3}$ After adjusting the preoperative variables by the propensity score matching, the operative mortality rates were not significantly different between the 2 groups. The difference in raw operative mortality is likely to be associated with differences in 


\section{IMH group}

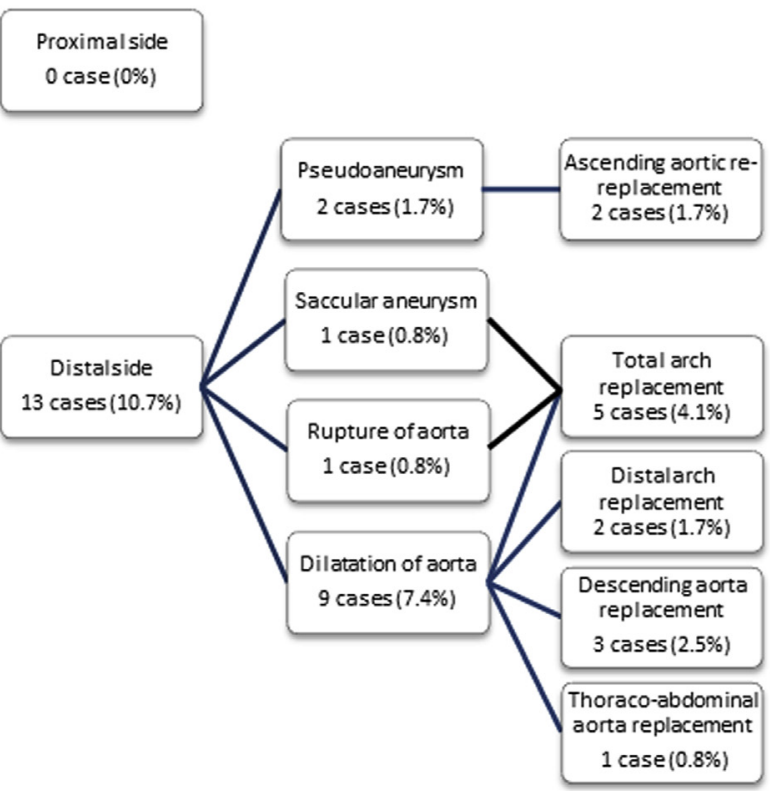

$A D$ group

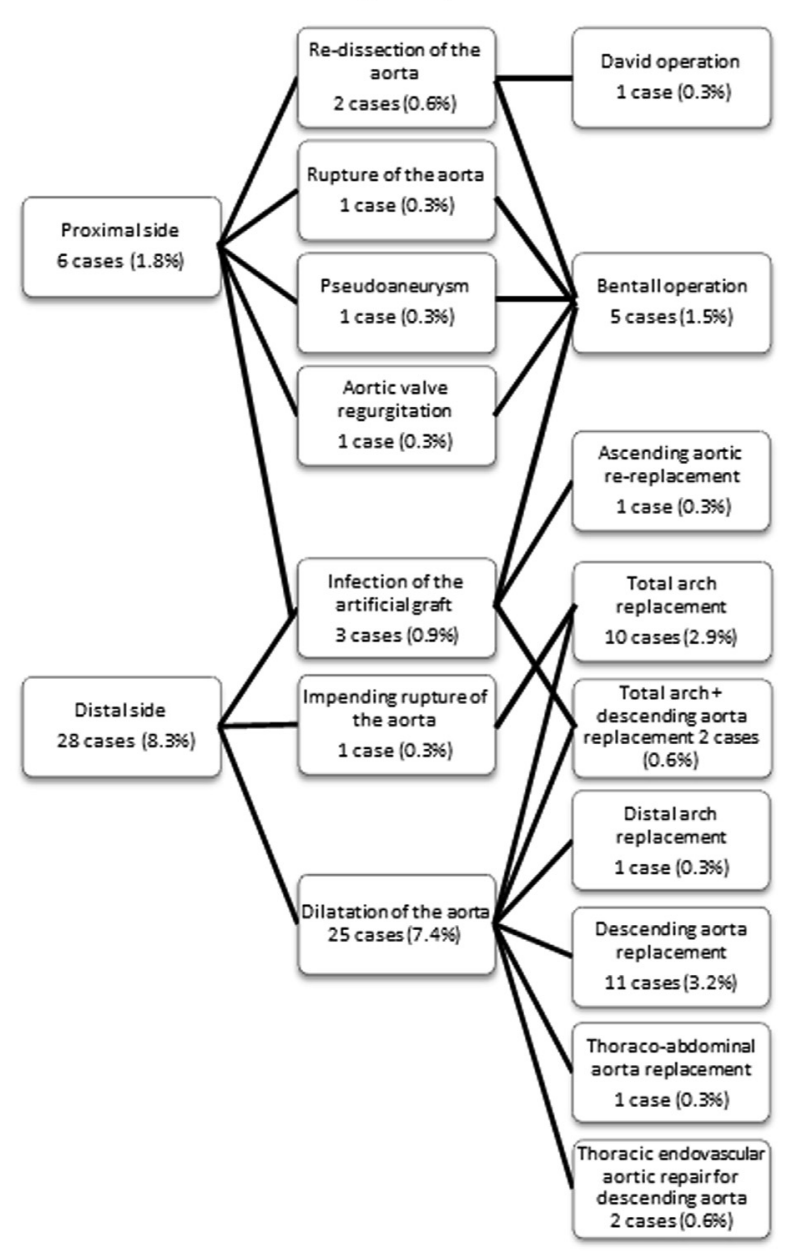

FIGURE 2. Reasons for aortic reoperation related to IMH or AD. IMH, Intramural hematoma; $A D$, aortic dissection.

preoperative conditions between the 2 groups. The operative mortality rates in the matched analysis $(0.8 \%$ vs $3.4 \%$ ) were somewhat different, although they were not statistically significant. No statistical difference might be due to small sample size. If there is a difference, it might be caused by a difference in operative variables. Patients in the IMH group underwent less complex surgery than those in the $\mathrm{AD}$ group, because organ malperfusion and aortic valve insufficiency were less frequently observed in the IMH group than in the AD group. Simpler procedures and more stable preoperative status are likely to lead to better operative outcomes of patients with IMH than patients with $\mathrm{AD}$.

In our study, 47 patients $(10.2 \%)$ required reoperation for aortic disease related to IMH or AD. Previous studies have reported that the late reoperation rate was $7.6 \%$ to $38 \%{ }^{18,21,22}$ We do annual follow-up CT scans for patients with IMH or AD who undergo surgery. We think that a longterm periodical follow-up is important because the late reoperation rate is not low in IMH or AD. Three patients
(6.4\%) underwent an emergency operation for rupture or impending rupture of aorta, and the other patients $(93.6 \%, 44 / 47)$ underwent an elective operation with stable condition. Early identification of patients who need reoperation of aortic disease related to IMH or $\mathrm{AD}$ and planning the reoperation may lead to good results. The reoperative mortality rate was $4.3 \%$ (2/47); 1 patient underwent ascending aortic re-replacement because of graft infection, and 1 patient underwent thoracoabdominal aorta replacement. Roselli and colleagues ${ }^{22}$ reported 305 patients who underwent reintervention after initial repair of ascending $\mathrm{AD}$ and concluded that graft infection, concomitant coronary artery bypass grafting, larger body mass index, a longer time between reinterventions, combined open arch and descending procedures, and lower distal anastomosis sites were risk factors for mortality. Recent studies also suggested that rigorous follow-up with early reintervention is important for improving outcomes. ${ }^{21,22}$

Our raw and matched data showed that the IMH group had higher 5-year survival after surgery than the AD group. 

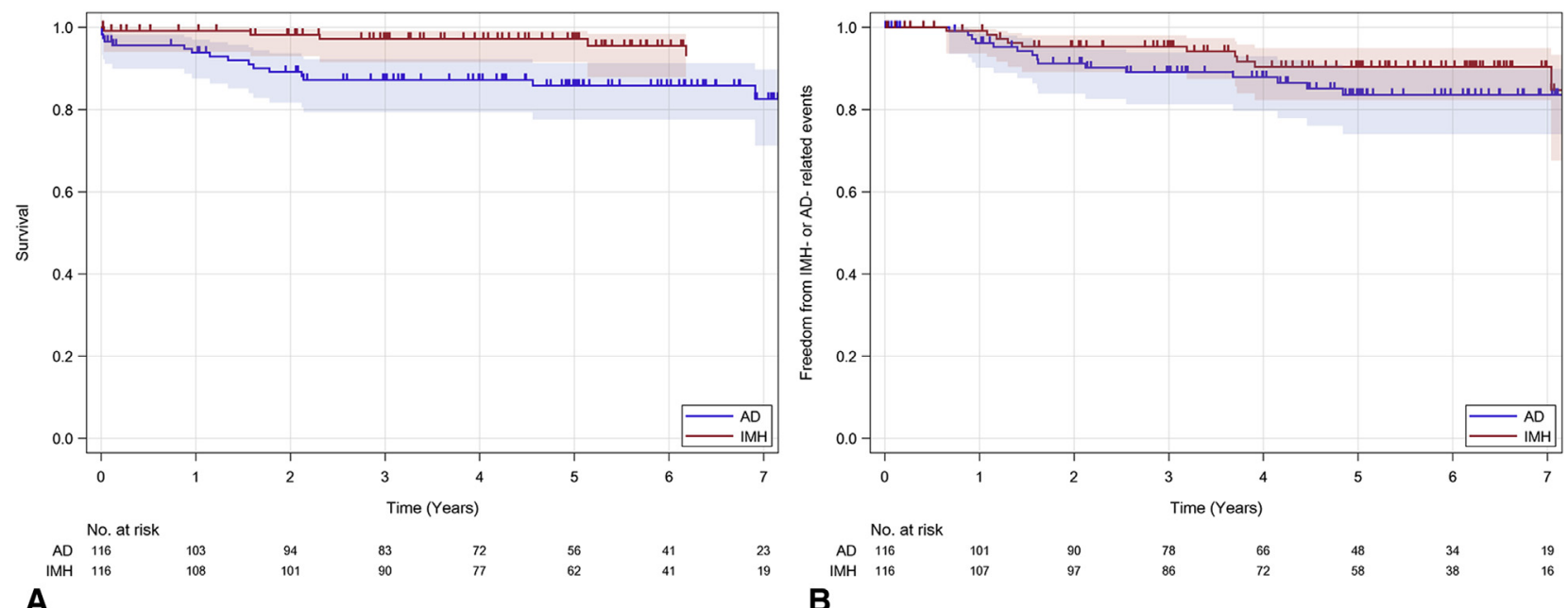

A

FIGURE 3. A, Kaplan-Meier analysis for freedom from any cause of death with $95 \%$ confidence limits in the matched patients. B, Kaplan-Meier analysis for freedom from IMH- or AD-related events with $95 \%$ confidence limits in the matched patients. AD, Aortic dissection; IMH, intramural hematoma.

The Cox proportional hazards model for midterm morality in propensity-matched patients showed that IMH was associated with lower midterm mortality after adjustment of operative variables. Estrera and colleagues ${ }^{8}$ reported that 1- and 5-year survivals of the patients with IMH were significantly higher than those of the patients with $\mathrm{AD}$ after adjustment for age and renal function. During the follow-up period, we had no IMH-related death. As mentioned earlier, identifying patients who require aortic reoperation without delay and performing elective reoperations might have led to good results.

\section{Study Limitations}

There are limitations of an observational nature in this study. We adjusted as much bias as we could by using the propensity score matching and multivariable analysis. This was a single-institute study, and there was selection bias of patients. Because most of our patients with $\mathrm{AD}$ were referred from other hospitals, very high-risk patients who were unlikely to be operable and those who did not want to have surgery might not have been included in our cohort. A larger study including surgical and nonsurgical IMH cases in the whole local area is expected to obtain a complete clinical picture of IMH.

\section{CONCLUSIONS}

Patients with IMH undergoing emergency surgery had less severe preoperative condition and less complex surgery compared with patients with AD. Emergency open surgery for type A IMH demonstrated low mortality and excellent 5-year survival. There is no significant difference in late IMH/AD-related event free rates. Patients with IMH should be followed up carefully, similar to patients with $\mathrm{AD}$.

\section{Conflict of Interest Statement}

Authors have nothing to disclose with regard to commercial support.

\section{References}

1. Gore I. Pathogenesis of dissecting aneurysm of the aorta. Arch Pathol Lab Med. $1952 ; 53: 142-53$

2. Stanson AW, Kazmier FJ, Hollier LH, Edwards WD, Pairolero PC, Sheedy PF, et al. Penetrating atherosclerotic ulcers of the thoracic aorta: natural history and clinicopathologic correlations. Ann Vasc Surg. 1986;1:15-23.

3. Uchida K, Imoto K, Takahashi M, Suzuki S, Isoda S, Sugiyama M, et al. Pathologic characteristics and surgical indications of superacute type A intramural hematoma. Ann Thorac Surg. 2005;79:1518-21.

4. Tittle SL, Lynch RJ, Cole PE, Singh HS, Rizzo JA, Kopf GS, et al. Midterm follow-up of penetrating ulcer and intramural hematoma of the aorta. $J$ Thorac Cardiovasc Surg. 2002;123:1051-9.

5. Song JK, Kim HS, Kang DH, Lim TH, Song MG, Park SW, et al. Different clinical features of aortic intramural hematoma versus dissection involving the ascending aorta. J Am Coll Cardiol. 2001;37:1604-10.

6. Uchida K, Imoto K, Karube N, Minami T, Cho T, Goda M, et al. Intramural hematoma should be referred to as thrombosed-type aortic dissection. Eur $J$ Cardiothorac Surg. 2013;44:366-9.

7. Kaji S, Akasaka T, Horibata Y, Nishigami K, Shono H, Katayama M, et al. Long-term prognosis of patients with type A aortic intramural hematoma. Circulation. 2002;106:1248-52.

8. Estrera AL, Sandhu HK, Leake SS, Charlton-Ouw KM, Afifi RO, Miller C III, et al. Early and late outcomes of acute type A aortic dissection with intramural hematoma. J Thorac Cardiovasc Surg. 2015;149:137-42.

9. Shimokawa T, Ozawa N, Takanashi S, Itoh T. Intermediate-term results of surgical treatment of acute intramural hematoma involving the ascending aorta. Ann Thorac Surg. 2008;85:982-6.

10. Matsushita A, Manabe S, Tabata M, Fukui T, Shimokawa T, Takanashi S Efficacy and pitfalls of transapical cannulation for the repair of acute type A aortic dissection. Ann Thorac Surg. 2012;93:1905-9.

11. Matsuyama S, Tabata M, Shimokawa T, Matsushita A, Fukui T, Takanashi S Outcomes of total arch replacement with stepwise distal anastomosis technique and modified perfusion strategy. J Thorac Cardiovasc Surg. 2012; 143:1377-81.

12. Austin PC. Propensity-score matching in the cardiovascular surgery literature from 2004 to 2006: a systematic review and suggestions for improvement. $J$ Thorac Cardiovasc Surg. 2007;134:1128-35.e3.

13. McMurry TL, Hu Y, Blackstone EH, Kozower BD. Propensity scores: methods, considerations, and applications in the Journal of Thoracic and Cardiovascular Surgery. J Thorac Cardiovasc Surg. 2015;150:14-9. 
14. Kay HP, Cheong L, Jin HC, Kiik S, Kwhanmien K, Young TL, et al. Prevalence of aortic intimal defect in surgically treated acute type A intramural hematoma. Ann Thorac Surg. 2008;86:1494-501.

15. Czerny M, Fleck T, Zimpfer D, Dworschak M, Hofmann W, Hutschala D, et al. Risk factors of mortality and permanent neurologic injury in patients undergoing ascending aortic and arch repair. J Thorac Cardiovasc Surg. 2003;126:1296-301.

16. Salis S, Mazzanti VV, Merli G, Salvi L, Tedesco CC, Veglia F, et al Cardiopulmonary bypass duration is an independent predictor of morbidity and mortality after cardiac surgery. J Cardiothorac Vasc Anesth. 2008;22:814-22.

17. Rampoldi V, Trimarchi S, Eagle KA, Nienaber CA, Oh JK, Bossone E, et al. Simple risk models to predict surgical mortality in acute type A aortic dissection: the international registry of acute aortic dissection score. Ann Thorac Surg. 2007; 83:55-61.

18. Stevens LM, Madsen JC, Isselbacher EM, Khairy P, Macgillivray TE, Hilgenberg $\mathrm{AD}$, et al. Surgical management and long-term outcomes for acute ascending aortic dissection. J Thorac Cardiovasc Surg. 2009;138:1349-57.
19. Esposito G, Cappabianca G, Bichi S, Cricco A, Albano G, Anzuini A. Hybrid repair of type A acute aortic dissections with the Lupiae technique: ten-year results. J Thorac Cardiovasc Surg. 2015;149:S99-104.

20. Hata M, Suzuki M. Sezai A, Niino T, Unosawa S, Furukawa N, et al. Less invasive quick replacement for octogenarians with type A acute aortic dissection. J Thorac Cardiovasc Surg. 2008;136:489-93.

21. Kimura N, Itoh S, Yuri K, Adachi K, Matsumoto H, Yamaguchi A, et al. Reoperation for enlargement of the distal aorta after initial surgery for acute type A aortic dissection. J Thorac Cardiovasc Surg. 2015;149:S91-8.

22. Roselli EE, Loor G, Jiayan He, Rafael AE, Rajeswaran J, Houghtaling PL, et al. Distal aortic interventions after repair of ascending dissection: the argument for a more aggressive approach. J Thorac Cardiovasc Surg. 2015; 149:S117-24.

Key Words: aortic dissection, intramural hematoma, surgery

Readers who found these articles interesting may also like to read the following papers found in recent and future issues of our sister publications, Seminars in Thoracic and Cardiovascular Surgery and Operative Techniques in Thoracic and Cardiovascular Surgery!

\section{Acquired: Aortic Disease}

Original Submission: Outcomes of Open Surgical Repair for Type B Dissecting Aortic Aneurysm with Alternative Methods in the Endovascular Stent Era. Mitsumasa Hata. Semin Thorac Cardiovasc Surg 2015; Summer; 27(2):106-112.

Editorial Commentary: It is Difficult to Compare Apples and Oranges: Acute and Chronic Type B Aortic Dissections, Complicated and Uncomplicated, are Different and Should be Treated as Such. Ourania Preventza. Semin Thorac Cardiovasc Surg 2015; Summer; 27(2):113-114.

News and Views: Treatment of Thoracic Aortic Aneurysm: Role of Earlier Intervention. Bulat A. Ziganshin. Semin Thorac Cardiovasc Surg 2015; Summer; 27(2);135-143. 